\title{
A novel strain of porcine deltacoronavirus in Vietnam
}

\author{
Van Phan Le ${ }^{1} \cdot$ Sok Song $^{3} \cdot$ Byung-Hyun An ${ }^{4} \cdot$ Gyu-Nam Park ${ }^{3} \cdot$ Ngoc Thach Pham $^{1}$. \\ Dinh Quyen $\mathrm{Le}^{2} \cdot$ Van Tam Nguyen ${ }^{2}$ Thi Thu Hang $\mathrm{Vu}^{2} \cdot \mathrm{Ki}^{3}$ Sun $\mathrm{Kim}^{3}$. \\ SeEun Choe ${ }^{3} \cdot$ Dong-Jun $\mathrm{An}^{3}$
}

Received: 23 April 2017 / Accepted: 20 August 2017 / Published online: 11 October 2017

(C) Springer-Verlag GmbH Austria 2017

\begin{abstract}
Two porcine deltacoronavirus (PDCoV) strains (Binh21 and HaNoi6) were isolated from two pig farms in North Vietnam. Phylogenetic analysis of the complete genomes and the Spike and Membrane genes revealed that the two Vietnam PDCoVs belong to the same lineage as PDCoVs from Thailand and Laos; however, the $N$ genes belonged to the same lineage as PDCoVs from the USA, Korea, China, and Hong Kong. The recombination detection program subsequently identified the major parent (S5011 strain) and minor parent (HKU15-44 strain) of the two Vietnam PDCoV strains $(\mathrm{p}<0.01)$.
\end{abstract}

Family Coronaviridae is divided into four genera: Alphacoronavirus, Betacoronavirus, Gammacoronavirus, and Deltacoronavirus [20]. Porcine deltacoronavirus (PDCoV) is an enveloped, single-stranded, positive-sense RNA virus with a genome approximately $25 \mathrm{~kb}$ in length. PDCoV comprises the 5'-untranslated region (UTR), open reading frames (ORFs) ORF1a and ORF1b, genes corresponding to

Handling Editor: Zhenhai Chen.

Van Phan Le and Sok Song: Co-first authors.

Dong-Jun An

andj67@korea.kr

1 Faculty of Veterinary Medicine, Vietnam National University of Agriculture, Hanoi, Vietnam

2 Research and Development Laboratory, AVAC Vietnam Company Limited (AVAC), Hanoi, Vietnam

3 Virus Disease Division, Animal and Plant Quarantine Agency, Gimcheon, Gyeongbuk-do 39660, Republic of Korea

4 Applied Chemistry and Biological Engineering, Ajou University, Suwon 443-749, Republic of Korea the following proteins: spike (S), envelope (E), membrane (M), non-structural protein 6 (Nsp6), nucleoprotein $(\mathrm{N})$, non-structure protein 7 (Nsp7); and finally the 3'-UTR [21]. The S glycoprotein contains two domains, S1 and S2, which play an important role in binding to specific host cell receptors [20]. Clinical observations in experimentally infected gnotobiotic and conventional nursing pigs have revealed that PDCoV induces acute, watery diarrhea, which is often accompanied by acute mild to moderate vomiting, ultimately leading to dehydration, loss of body weight, lethargy, and death $[1,4,11]$. PDCoV was first identified in pig samples collected in Hong Kong in 2012 [21]. Emergence of PDCoV on pig farms in the USA was reported in 2014 and rapidly spread across the country [7]. Since then, the virus has been detected in Korea, China, Thailand, and Lao PDR [2, 6, 9, 15]. Phylogenetic analysis of the $S, M$, and $N$ genes from two strains (P29_15_VN_1_1215 and P30_15_VN_1215) detected on pig farms in Dong Nai and Baria provinces in South Vietnam revealed that they belonged to the Hong Kong, Korea, and USA lineages [14].

The objective of the present study was to investigate circulating PDCoV strains in North Vietnam and to analyze their complete genome sequences. In October and December 2015, two cases of diarrhea were reported on pig farms located in Phu Xuyen-Ha Noi province and Thai-Thuy-Thai Binh province, both of which are located in northern Vietnam. The pig farm in Phu Xuyen-Ha Noi bred a farrowto-finisher herd of 634 head. Clinical symptoms included vomiting and watery diarrhea, resulting in the death of some piglets less than 30 days old. Morbidity was $100 \%$ (80/80) for piglets, $93.8 \%$ (60/64) for weaning pigs, $72.3 \%$ (340/470) for growing pigs, and 65\% (13/20) for gilts and sows. Mortality was $36.2 \%$ (29/80) for piglets and $13.3 \%$ (8/64) for weaning pigs; none of the growing pigs, gilts, or sows died. The pig farm in Thai-Thuy-Thai Binh province 
bred about 5,000 head, all aged from 2 to 6 months. Clinical symptoms were noted for about 14 days, and pigs of all ages were infected and had diarrhea. Morbidity was about $65 \%$ $(3,250 / 5,000)$; however, the only clinical sign was diarrhea and no pigs died. Diarrheal fecal samples $(\mathrm{n}=26)$ collected from the two pig farms were subjected to RT-PCR to test for the Spike $(S)$ gene of porcine epidemic diarrhea virus (PEDV), the Nucleocapsid $(N)$ gene of transmissible gastroenteritis virus (TGEV), and the $N$ gene of PDCoV, as previously described $[5,13,19]$. Viral RNA was extracted from feces using TRIzol $\mathrm{LS}^{\mathrm{b}}$, according to the manufacturer's instructions, and products of the expected size were cloned into the pGEM-T Vector System II (Promega, Cat. No. A3610, USA). The cloned gene was then sequenced on an ABI Prism ${ }^{\circledR} 3730 x \mathrm{x}$ DNA Sequencer at the Macrogen Institute (Macrogen Co., Ltd.) using T7 and SP6 sequencing primers. Ten fecal samples from 21-day-old piglets at the farm in Phu Xuyen-Ha Noi were collected in October 2015, and all were positive for PDCoV; while none were positive for PEDV or TGEV. Sequence analysis of the PDCoV $N$ genes from the ten samples revealed $99.8-100 \%$ identity. Sixteen fecal samples (from pigs aged 2 to 5 months) were collected from Thai Thuy-Thai Binh in December 2015, and 14 were identified as PDCoV-positive by RT-PCR; while none were positive for PEDV or TGEV. The PDCoV $N$ genes from these 14 samples were $99.7-100 \%$ identical at the nucleotide (nt) level. We sequenced the complete genome of one (HaNoi6) of the ten strains detected at Phu Xuyen-Ha Noi and one (Binh21) of the 14 strains detected at Thai-Thuy-Thai Binh and submitted them to GenBank under accession numbers KX834351-KX834352. The complete genome sequences were then aligned using the CLUSTALX alignment program [17].
The HaNoi6 and Binh21 strains are 25,406 nt in length and $99.9 \%$ identical at the nt level. The ORF1a/1b and $S$ genes of HaNoi6 and Binh21 are 99.9\% and 99.8\% identical, respectively, whereas the 5' and 3' UTR and E, $M, N, N S P 6$, NSP7 genes are $100 \%$ identical (Table 1). The complete genome of Binh 21 strain showed $98.4 \%$ identity at the nt level with the S5011 and TT_1115 stains from Thailand and the P1_16BTL_0115 strain from Laos (Table 1). The $S$ genes of the Binh21 and HaNoi6 strains were $99.8 \%$ identical at the nt level, but only $96.6-97.1 \%$ identical to strains from the USA, Korea, China, and Thailand. Interestingly, the S protein of Binh21 was 98.1-98.3\% identical at the amino acid level to strains HKU15-44, Minnesota 159, and KNU14-04, but only $97.4 \%$ identical to strains from Thailand and Laos (Table 1). However, phylogenetic analysis of the S gene/ protein at the nucleotide and amino acid level revealed that Vietnam Binh21 and HaNoi6 strains were included in the same group with Thailand and Laos strains. The reason for this discrepancy between amino acid identity and phylogenetic tree analysis for the $\mathrm{S}$ gene is not clear, but it might be due to several unique sequences that determine each cluster on the phylogenetic tree. The amino acid sequences of the $\mathrm{E}$ and $\mathrm{M}$ proteins of HaNoi6 and Binh21 are 100\% identical to those of the S5011, CH/S27, HKU15-44, Minnesota159, and KNU14-04 strains. The E and M proteins are transmembrane proteins associated with viral envelope formation and release [20]. Compared with the HKU15-44 strain, the HaNoi6 and Binh21 strains lack a three nt (CTA) segment in the 5' UTR (110-112 bp), six nt (TTTGAA) and nine nt (GCCGGTTGG) segments in ORF1a/1b (1,732-1,737 bp and 2,803-2,811 bp, respectively), and have a single nt (C) inserted in the 3' UTR (25,042 bp). Also, compared with the S5011 strain, the HaNoi 6 and Binh21 strains have a single
Table 1 Comparison of the nucleotide sequence of Binh21 strain with those of reference viruses obtained from GenBank

\begin{tabular}{|c|c|c|c|c|c|c|c|c|c|c|}
\hline \multirow[t]{2}{*}{ Strains } & \multicolumn{10}{|c|}{ Nucleotide sequence/amino acids sequence homology (\%) } \\
\hline & Full genome & 5' UTR & ORF1a/1b & $\mathrm{S}$ & $\mathrm{E}$ & M & $\mathrm{N}$ & NSP6 & NSP7 & 3' UTR \\
\hline HaNoi6 & 99.9 & 100 & $\begin{array}{l}99.9 \\
199.9\end{array}$ & $\begin{array}{l}99.8 \\
199.8\end{array}$ & $\begin{array}{l}100 \\
/ 100\end{array}$ & $\begin{array}{l}100 \\
/ 100\end{array}$ & $\begin{array}{l}100 \\
/ 100\end{array}$ & $\begin{array}{l}100 \\
/ 100\end{array}$ & $\begin{array}{l}100 \\
/ 100\end{array}$ & 100 \\
\hline TT_1115 & 98.4 & 98.8 & $\begin{array}{l}98.8 \\
199.0\end{array}$ & $\begin{array}{l}96.8 \\
197.4\end{array}$ & $\begin{array}{l}99.6 \\
/ 100\end{array}$ & $\begin{array}{l}98.7 \\
/ 99.5\end{array}$ & $\begin{array}{l}97.9 \\
198.5\end{array}$ & $\begin{array}{l}98.9 \\
198.9\end{array}$ & $\begin{array}{l}97.0 \\
192.0\end{array}$ & 96.9 \\
\hline S5011 & 98.4 & 98.6 & $\begin{array}{l}98.8 \\
198.9\end{array}$ & $\begin{array}{l}96.9 \\
197.4\end{array}$ & $\begin{array}{l}99.6 \\
/ 100\end{array}$ & $\begin{array}{l}99.0 \\
/ 100\end{array}$ & $\begin{array}{l}97.0 \\
/ 98.8\end{array}$ & $\begin{array}{l}98.9 \\
198.9\end{array}$ & $\begin{array}{l}97.1 \\
/ 92.5\end{array}$ & 96.9 \\
\hline BTL_0115 & 98.4 & 98.6 & $\begin{array}{l}98.7 \\
197.8\end{array}$ & $\begin{array}{l}96.9 \\
197.4\end{array}$ & $\begin{array}{l}99.6 \\
/ 100\end{array}$ & $\begin{array}{l}99.0 \\
/ 99.5\end{array}$ & $\begin{array}{l}98.1 \\
/ 98.5\end{array}$ & $\begin{array}{l}98.9 \\
198.9\end{array}$ & $\begin{array}{l}97.3 \\
93.0\end{array}$ & 96.9 \\
\hline $\mathrm{CH} / \mathrm{S} 27$ & 98.0 & 98.8 & $\begin{array}{l}98.1 \\
198.7\end{array}$ & $\begin{array}{l}96.6 \\
197.9\end{array}$ & $\begin{array}{l}98.8 \\
/ 100\end{array}$ & $\begin{array}{l}99.2 \\
/ 100\end{array}$ & $\begin{array}{l}98.9 \\
199.4\end{array}$ & $\begin{array}{l}98.9 \\
197.8\end{array}$ & $\begin{array}{l}98.6 \\
196.0\end{array}$ & 98.4 \\
\hline HKU15-44 & 97.9 & 98.8 & $\begin{array}{l}97.5 \\
197.8\end{array}$ & $\begin{array}{l}97.1 \\
198.1\end{array}$ & $\begin{array}{l}99.6 \\
/ 100\end{array}$ & $\begin{array}{l}99.5 \\
/ 100\end{array}$ & $\begin{array}{l}99.2 \\
199.7\end{array}$ & $\begin{array}{l}99.2 \\
198.9\end{array}$ & $\begin{array}{l}99.1 \\
197.5\end{array}$ & 98.7 \\
\hline Minnesota159 & 97.7 & 98.6 & $\begin{array}{l}97.4 \\
198.1\end{array}$ & $\begin{array}{l}96.8 \\
198.3\end{array}$ & $\begin{array}{l}99.2 \\
/ 100\end{array}$ & $\begin{array}{l}99.2 \\
/ 100\end{array}$ & $\begin{array}{l}98.9 \\
199.7\end{array}$ & $\begin{array}{l}98.9 \\
197.8\end{array}$ & $\begin{array}{l}98.6 \\
196.0\end{array}$ & 98.4 \\
\hline KNU14-04 & 97.7 & 98.7 & $\begin{array}{l}97.3 \\
198.0\end{array}$ & $\begin{array}{l}96.8 \\
/ 98.3\end{array}$ & $\begin{array}{l}99.2 \\
/ 100\end{array}$ & $\begin{array}{l}98.9 \\
/ 100\end{array}$ & $\begin{array}{l}98.9 \\
199.7\end{array}$ & $\begin{array}{l}98.9 \\
197.8\end{array}$ & $\begin{array}{l}98.8 \\
/ 96.5\end{array}$ & 98.2 \\
\hline
\end{tabular}



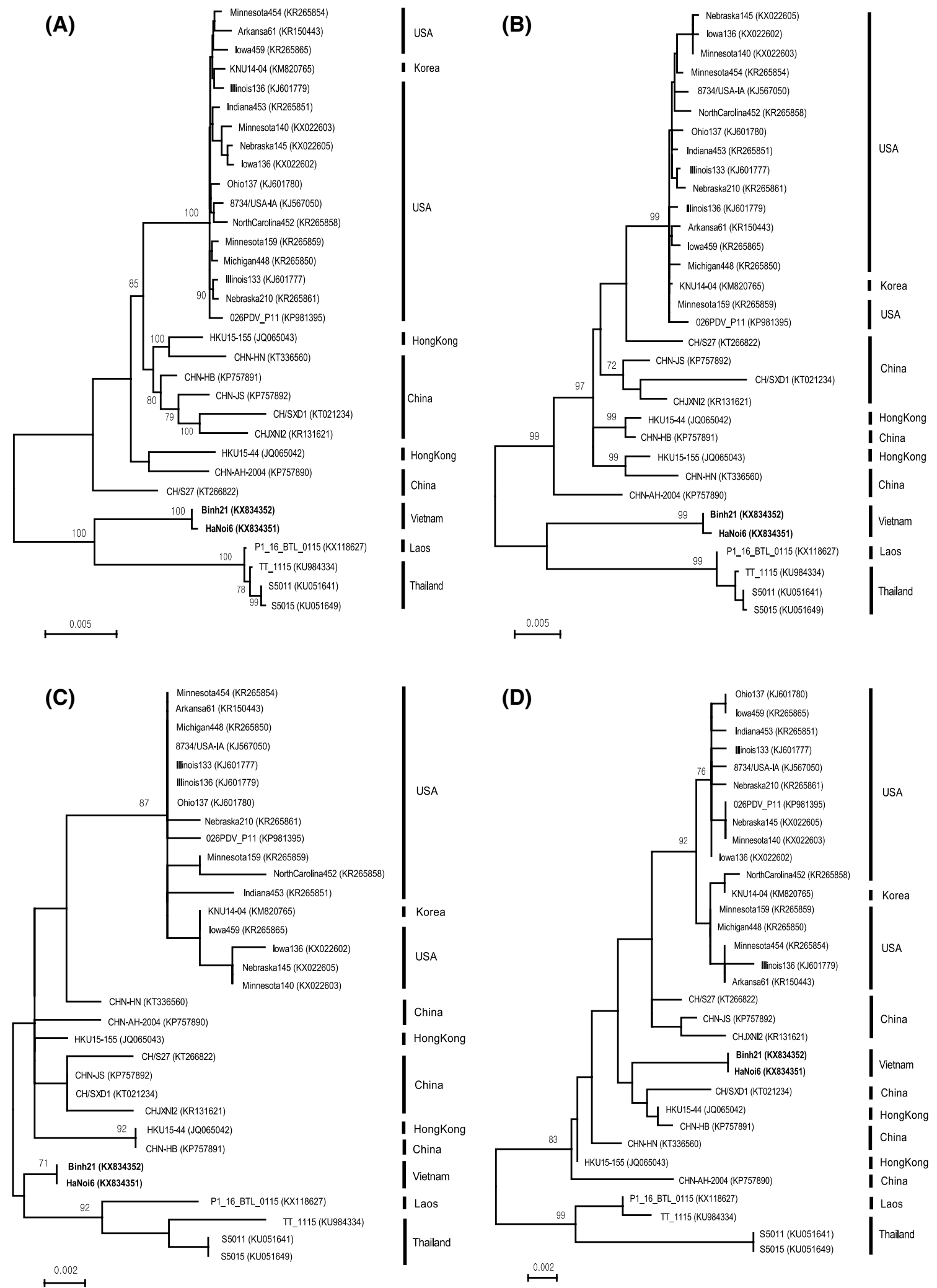

Fig. 1 Phylogenetic analysis of 32 PDCoV strains based on the nucleotide sequences of the complete genome (A) and the $S$ (B), $M(\mathrm{C})$, and $N(\mathrm{D})$ genes. The trees were constructed using the ML method (based on the Tamura-Nei model) and bootstrap analysis $(n=$

1,000 ) in Mega 6.06 software. Bootstrap values $>70 \%$ are shown at the branch points. The scale bar indicates the number of nucleotide substitutions per site. The two Vietnamese PDCoV strains are marked in bold 
(A)

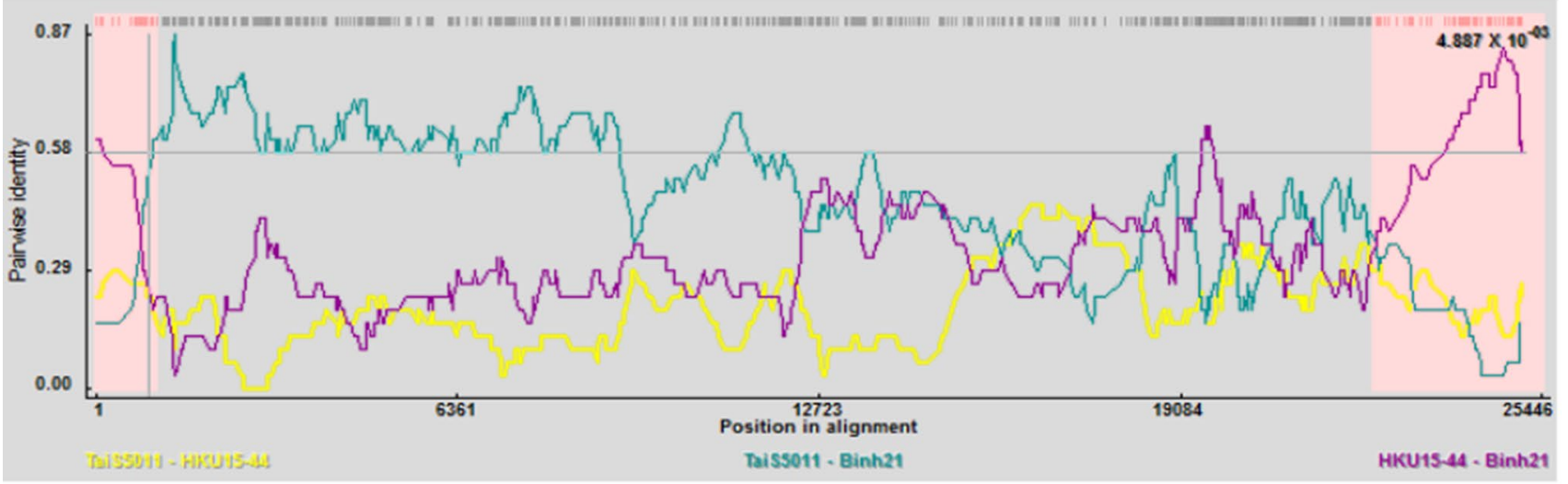

(B)

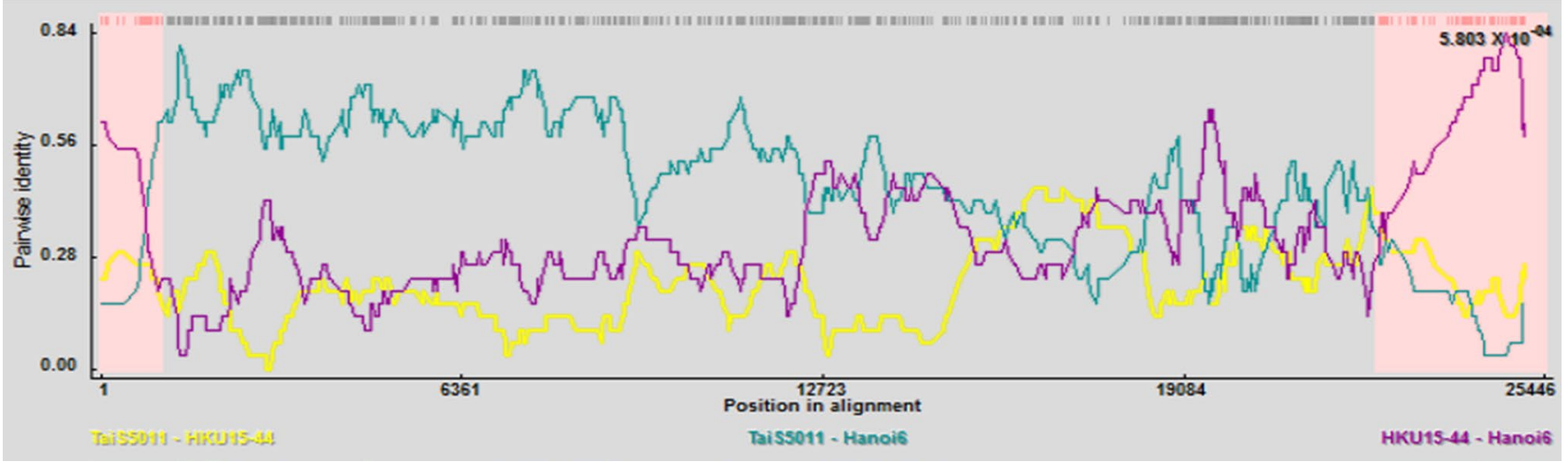

Fig. 2 Recombination analysis of the Binh21 (A) and Hanoi6 (B) strains. Possible breakpoints in the recombination event between S5011 and HKU15-44 were estimated using the RDP method and

nt (A) inserted in the 5' UTR (298 bp). After Clustal X multiple sequence alignment, three phylogenetic trees representing complete genome sequences as well as sequences of the $\mathrm{S}$ and $\mathrm{M}$ genes of $32 \mathrm{PDCoV}$ strains from GenBank, including the two Vietnam PDCoV strains identified herein, were generated using the maximum-likelihood (ML) method, with the Tamura-Nei model and bootstrap analysis $(\mathrm{n}=$ 1000). This was performed using the MEGA 6.06 software with default parameters [16]. Phylogenetic analysis of the complete genome, $\mathrm{S}$ gene, and $\mathrm{M}$ gene sequences showed that the two Vietnam PDCoV strains belong to the same lineage as three Thailand PDCoVs and one Laos PDCoV (Fig. 1A-C). Analysis of Thailand's PDCoV strains suggested that they clustered as a novel lineage of PDCoV that was separate from the US-like and China-like lineage PDCoVs [8]. The finding also suggested that the Thailand PDCoV isolates could have evolved from the same ancestor as other PDCoV strains but had differentiated at some point in the past [8]. The origin and source of the PDCoVs introduced into North Vietnam is currently unknown, but phylogenetic analysis suggests that Hanoi6 and Binh21 are confirmed by the BootScan, MaxChi, and Chimaera applications in the RDP program $(p<0.01)$

closely related to Thailand and Laos strains, a finding supported by the close geographic proximity of these regions. However, the ML tree revealed that the $\mathrm{N}$ genes of Hanoi6 and Binh21 belong to the same lineage as strains from the USA, Korea, China, and Hong Kong (Fig. 1D). The N protein is involved in viral replication, function, and pathogenesis [12]. Therefore the two Vietnam PDCoV strains were analyzed using the recombination detection program (RDP). The recombination breakpoint was determined using the RDP method and confirmed statistically using the BootScan, MaxChi, and Chimaera applications $(p<0.01)$. The major parent and minor parent were identified as S5011 and HKU15-44, respectively $(p<0.01)$. BootScan analysis predicted the potential breakpoints in HaNoi6 and Binh21 to be at nt 1,007 and nt 23,846 (Fig. 2). Recombination events are often reported in PEDV studies, and the majority are intra-recombinants of different lineages of the same type of enteric coronavirus $[3,18]$. A recent study of possible recombination events in $\mathrm{PDCoV}$ strains reported that the CHN-GD16-05 strain belonged to American and Korean lineages, while the CHN-GD16-03 strain was similar to a 
Thailand strain, but only in terms of the $S$ gene [10]. The recently emerging PDCoV strains in Thailand are highly virulent, causing a mortality rate of $19.22 \%$ in pig farms [2]. The HaNoi6 strain, belonging to the same lineage as Thailand PDCoV strains, has a mortality rate in piglets and weaning pigs of $36.2 \%$ and $13.3 \%$, respectively. HaNoi6 was also observed in gilts and sows, indicating that the pathogenicity of PDCoV is not confined to piglets.

In conclusion, genetic analyses, based on complete genome sequences, demonstrated that HaNoi6 and Binh21 strains from North Vietnam are similar to PDCoV strains from Thailand and Laos. Like Thailand's PDCoV strains, the HaNoi6 strain is highly virulent and pathogenic to piglets. Recombination events in the two Vietnamese PDCoV strains were identified in the $N$ gene region. The genetic lineages of PDCoV strains from different countries appears to differ, suggesting that they may recombine and evolve continuously to generate diverse genotypes.

Acknowledgements This work was supported by the Vietnam National Foundation for Science and Technology Development (NAFOSTED) under grant number 106-NN.04-2014.16, and by a grant (Project Code No. B-1543083-2015-17-01) from the Animal and Plants Quarantine Agency (QIA), Ministry of Agriculture, Food and Rural Affairs (MAFRA), Republic of Korea (2015).

\section{References}

1. Chen Q, Gauger P, Stafne M, Thomas J, Arruda P, Burrough E, Madson D, Brodie J, Magstadt D, Derscheid R, Welch M, Zhang J (2015) Pathogenicity and pathogenesis of a United States porcine deltacoronavirus cell culture isolate in 5-day-old neonatal piglets. Virology 482:51-59

2. Janetanakit T, Lumyai M, Bunpapong N, Boonyapisitsopa S, Chaiyawong S, Nonthabenjawan N, Kesdaengsakonwut S, Amonsin A (2016) Porcine deltacoronavirus, Thailand, 2015. Emerg Infect Dis 22:757-759

3. Jarvis MC, Lam HC, Zhang Y, Wang L, Hesse RA, Hause BM, Viasova A, Wang Q, Zhang J, Nelson MI, Murtaugh MP, Marthaler D (2015) Genomic and evolutionary inferences between American and global strains of porcine epidemic diarrhea virus. Prev Vet Med 123:175-184

4. Jung K, Hu H, Eyerly B, Lu Z, Chepngeno J, Saif LJ (2015) Pathogenicity of 2 porcine deltacoronavirus strains in gnotobiotic pigs. Emerg Infect Dis 21:650-654

5. Kim O, Choi C, Kim B, Chae C (2000) Detection and differentiation of porcine epidemic diarrhoea virus and transmissible gastroenteritis virus in clinical samples by multiplex RT-PCR. Vet Rec 146:637-640

6. Lee S, Lee C (2016) Complete genome characterization of Korean porcine deltacoronavirus strain KOR/KNU14-04/2014. Genome Announc 2(6):e01191-e0119114
7. Li G, Chen Q, Harmon KM, Yoon KJ, Schwartz KJ, Hoogland MJ, Gauger PC, Main RG, Zhang J (2014) Full-Length genome sequence of porcine deltacoronavirus strain USA/IA/2014/8734. Genome Announc 2(2):e00278-e0027814

8. Lorsirigool A, Saeng-Chuto K, Madapong A, Temeeyasen G, Tripipat T, Kaewprommal P, Tantituvanont A, Piriyapongsa J, Nilubol D (2017) The genetic diversity and complete genome analysis of two novel porcine deltacoronavirus isolates in Thailand in 2015. Virus Genes 53:240-248

9. Lorsirigool A, Saeng-Chuto K, Temeeyasen G, Madapong A, Tripipat $\mathrm{T}$, Wegner $\mathrm{M}$, Tuntituvanont $\mathrm{A}$, Intrakamhaeng $\mathrm{M}$, Nilubol D (2016) The first detection and full-length genome sequence of porcine deltacoronavirus isolated in Lao PDR. Arch Virol 161:2909-2911

10. Ma K, Feng J, Chen G, Li D, Zhou L, Bai Y, Wu Q, Ma J (2017) The detection and phylogenetic analysis of porcine deltacoronavirus from Guangdong Province in Southern China. Transbound Emerg Dis. doi:10.1111/tbed.12644 (Epub ahead of print)

11. Ma Y, Zhang Y, Liang X, Lou F, Oglesbee M, Krakowka S, Li J (2015) Origin, evolution, and virulence of porcine deltacoronaviruses in the United States. mbio 6:e00064

12. McBride R, van Zyl M, Fielding BC (2014) The coronavirus nucleocapsid is a multifunctional protein. Viruses 6:2991-3018

13. Park SJ, Moon HJ, Yang JS, Lee CS, Song DS, Kang BK, Park BK (2007) Sequence analysis of the partial spike glycoprotein gene of porcine epidemic diarrhea viruses isolated in Korea. Virus Genes 35:321-332

14. Saeng-Chuto K, Lorsirigool A, Temeeyasen G, Vui DT, Stott CJ, Madapong A, Tripipat T, Wegner M, Intrakamhaeng M, Chongcharoen W, Tantituvanont A, Kaewprommal P, Piriyapongsa J, Nilubol D (2017) Different lineage of porcine deltacoronavirus in Thailand, Vietnam and Lao PDR in 2015. Transbound Emerg Dis 64:3-10

15. Song D, Zhou X, Peng Q, Chen Y, Zhang F, Huang T, Zhang T, Li A, Huang D, Wu Q, He H, Tang Y (2015) Newly emerged porcine deltacoronavirus associated with diarrhoea in swine in China: identification, prevalence and full-length genome sequence analysis. Transbound Emerg Dis 62:575-580

16. Tamura K, Stecher G, Peterson D, Filipski A, Kumar S (2013) MEGA6: molecular evolutionary genetics analysis version 6.0. Mol Biol Evol 30:2725-2729

17. Thompson JD, Gibson TJ, Plewniak F, Jeanmougin F, Higgins DG (1997) The CLUSTAL_X windows interface: flexible strategies for multiple sequence alignment aided by quality analysis tools. Nucleic Acids Res 25:4876-4882

18. Tian P, Jin Y, Xing G, Qv LL, Huang YW, Zhou JY (2014) Evidence of recombinant strains of porcine epidemic diarrhea virus, United States, 2013. Emerg Infect Dis 20:1731-1734

19. Wang L, Byrum B, Zhang Y (2014) Detection and genetic characterization of deltacoronavirus in pigs, Ohio, USA, 2014. Emerg Infect Dis 20:1227-1230

20. Woo PC, Huang Y, Lau SK, Yuen KY (2010) Coronavirus genomics and bioinformatics analysis. Viruses 2:1804-1820

21. Woo PC, Lau SK, Lam CS, Lau CC, Tsang AK, Lau JH, Bai R, Teng JL, Tsang CC, Wang M, Zheng BJ, Chan KH, Yuen KY (2012) Discovery of seven novel Mammalian and avian coronaviruses in the genus deltacoronavirus supports bat coronaviruses as the gene source of alphacoronavirus and betacoronavirus and avian coronaviruses as the gene source of gammacoronavirus and deltacoronavirus. J Virol 86:3995-4008 